\title{
Molecular mechanism of the Neurospora circadian oscillator
}

\author{
Jinhu Guo, Yi Liu ${ }^{凶}$ \\ Department of Physiology, University of Texas Southwestern Medical Center, 5323 Harry Hines Blvd. Dallas, TX 75390-9040, \\ USA \\ C Correspondence: Yi.Liu@UTsouthwestern.edu \\ Received February 24, 2010 Accepted March 31, 2010
}

\begin{abstract}
Circadian clocks are the internal time-keeping mechanisms for organisms to synchronize their cellular and physiological processes to the daily light/dark cycles. The molecular mechanisms underlying circadian clocks are remarkably similar in eukaryotes. Neurospora crassa, a filamentous fungus, is one of the best understood model organisms for circadian research. In recent years, accumulating data have revealed complex regulation in the Neurospora circadian clock at transcriptional, posttranscriptional, post-translational and epigenetic levels. Here we review the recent progress towards our understanding of the molecular mechanism of the Neurospora circadian oscillator. These advances have provided novel insights and furthered our understanding of the mechanism of eukaryotic circadian clocks.
\end{abstract}

KEYWORDS circadian clock, circadian oscillator, Neurospora crassa, eukaryotes

\section{INTRODUCTION}

Circadian clocks are intrinsic molecular devices that allow most eukaryotic and some prokaryotic organisms to adjust their molecular, cellular and behavioral activities to the daily changing environmental factors including light and temperature, caused by the self-rotation of the earth (Young and Kay, 2001; Dunlap and Loros, 2004; Foster, 2004; Heintzen and Liu, 2007). The molecular machineries that generate the endogenous daily rhythmicities are called circadian oscillators. A variety of organisms such as Cyanobacteria, fungi, plants (Arabidopsis), and animals (e.g., Drosophila, and mammals) (Levine, 2004; Bell-Pedersen et al., 2005;
Reppert, 2006; Williams, 2007; Harmer, 2009) have been employed as model organisms to study the molecular mechanism of circadian clocks. Despite the difference in clock mechanisms, the core eukaryotic circadian oscillators consisting of negative feedback loops share many similarities in different organisms (Dunlap and Loros, 2004; Foster, 2004; Bell-Pedersen et al., 2005). In Neurospora, Drosophila, and mammals, heterodimeric complexes of two PER-ARNT-SIM (PAS) domain-containing transcription factors act as positive elements that activate the expression of negative elements. On the other hand, the negative elements repress their own transcription by inhibiting the activity of the positive elements. The cyclic activation, repression and reactivation of circadian negative elements generate the autonomous oscillation, which controls the circadian output pathway by regulating the expression of downstream clock-controlled genes (ccgs) (Bell-Pedersen et al., 1996; Vitalini et al., 2004; BellPedersen et al., 2005; Heintzen and Liu, 2007).

The filamentous fungus Neurospora crassa has a distinguished history as a well-established circadian model organism (Loros and Dunlap, 2001; Dunlap and Loros, 2004). More than 40 years ago, a band (bd) Neurospora strain was isolated. It exhibits robust circadian rhythm of asexual spores (conidia) formation and has been widely used for circadian research because of its easily visible conidiation rhythmicity (Sargent et al., 1966; Sargent and Woodward, 1969). The mutation responsible for the bd phenotype was later shown to be a mutation in the ras-1 gene (Belden et al., 2007a). Today, Neurospora continues to be one of the best established model organisms for circadian clock research.

Because the light entrainment and circadian output pathways of the Neurospora systemhave been extensively reviewed elsewhere (Liu, 2003; Liu and Bell-Pedersen, 2006; Dunlap et al., 2007; Heintzen and Liu, 2007; de Paula et al., 2008), we will focus on the recent advances of the 
molecular mechanism of the Neurospora circadian oscillator in this review.

\section{THE CORE CIRCADIAN OSCILLATOR OF THE NEUROSPORA CIRCADIAN CLOCK}

Circadian oscillators are self-sustained pacemakers that drive diverse molecular circadian rhythms (Bell-Pedersen et al., 2005). Circadian oscillators consist of positive and negative components which form negative feedback loops. The positive elements function to activate the transcription of the negative elements. On the other hand, the negative elements act to repress their own transcription by inhibiting the activity of the positive elements. In the Neurospora circadian clock oscillator, FREQUENCY (FRQ), FRQ-INTERACTING RNA HELICASE (FRH), WHITE COLLAR 1 (WC-1) and WHITE COLLAR (WC-2) are the core components of Neurospora circadian clock (Fig. 1) (Ballario et al., 1996; Linden and Macino, 1997; Talora et al., 1999; Cheng et al., 2002, 2003b,
2005). Both WC-1 and WC-2 proteins contain PAS domains and form the WC complex (WCC), which binds to frq promoter and activate its transcription as positive conponents (Aronson et al., 1994a, b; Crosthwaite et al., 1997; Cheng et al., 2001b, 2003b; Froehlich et al., 2003; He et al., 2005b; Liu and Bell-Pedersen, 2006).

FRQ is the key negative element in Neurospora circadian oscillator. The full length $F R Q$ contains 989 amino acid residues (Aronson et al., 1994a). There are two forms of $F R Q$, the large $F R Q$ (IFRQ) and small FRQ (sFRQ), which differ by 100 amino acid at the N' terminus due to alternative splicing (Liu et al., 1997; Colot et al., 2005; Diernfellner et al., 2007). The alternative splicing of frq functions to tune the period length and resets the clock in response to ambient temperature. The frq gene locus also transcribes natural antisense transcripts (NATs), which contributes to the light entrainment of the clock (Kramer et al., 2003).

$F R Q$ protein self-associates via the coil-coil region near the $N^{\prime}$ terminus (Cheng et al., 2001a), and all FRQ protein is in

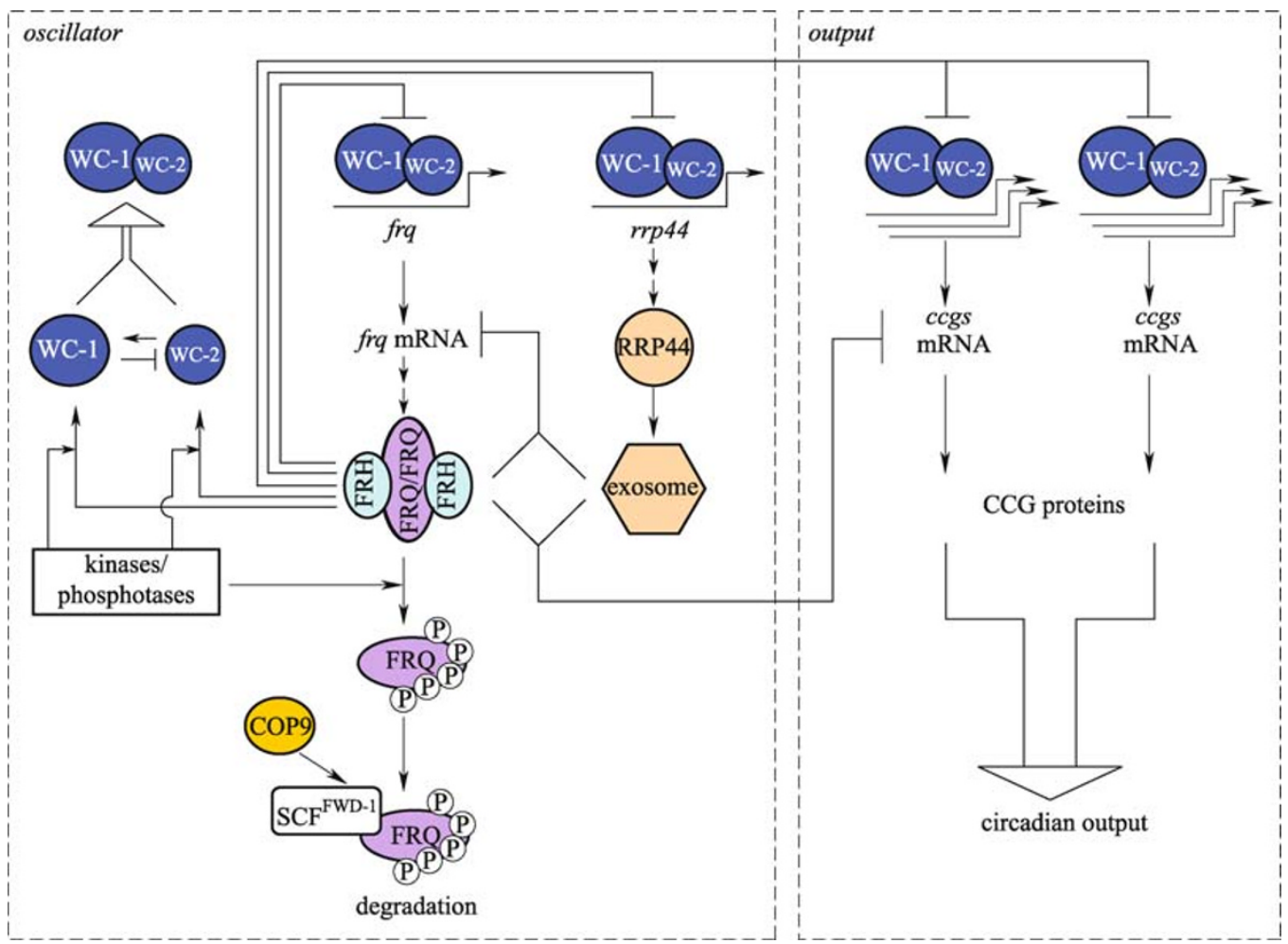

Figure 1. Molecular network of the Neurospora circadian clock. WC-1 and WC-2, two PAS-domain containing proteins form the White Collar complex (WCC) which binds the frq gene promoter and activate frq transcription. FRQ protein associates with FRH to form the FRQ-FRH complex (FFC). FFC recruits kinases to phosphorylate WC proteins which leading to dissociation of WCC from the frq promoter and inhibition of frq transcription. In the meantime, FRQ promotes the steady-state levels of WC-1 and WC-2, forming the positive feedback loop. Upon progressive phosphorylation events, hyperphosphorylated FRQ is degraded by $26 \mathrm{~S}$ proteasome either through the pathway involving FWD-1, or an unknown pathway independent of FWD-1. The signalosome COP9 regulates circadian clock by promoting the stability of $\mathrm{SCF}^{\mathrm{FWD}-1}$. The expression of $r r p 44$, which encoding the catalytic subunit of exosome, is rhythmically regulated by FFC. Exosome and FFC function to facilitate the decay of frq mRNA and a subset of $c c g$ mRNAs, forming a post-transcriptional negative feedback loop. CSW-1 (Clock-Switch 1) regulates the accessibility of frq promoter to the transcription factors at the epigenetic level. 
complex with FRH to form the FRQ-FRH complex (FFC). In addition, FRQ binds to FRH over the entire circadian cycles (Baker et al., 2009). More importantly, downregulation of FRH completely abolishes circadian rhythmicity (Cheng et al., 2005). FFC enters the nucleus and dissociates WCC from the fra promoter by promoting phosphorylation of WCC through the recruitment of the casein kinases, resulting in the suppression of frq transcription and closing of the transcription-based negative feedback loop (Cheng et al., 2005; He et al., 2005b; Schafmeier et al., 2005; He et al., 2006; Guo et al., 2009). These results indicate that FRH is also an essential component of the circadian negative feedback loop.

After its synthesis, FRQ protein undergoes progressive phosphorylation and become extensively phosphorylated before its degradation mediated by ubiquitin/proteasome (He et al., 2003; He and Liu, 2005a). Elimination of FRQ in turn liberates WCC and its reactivation of fra transcription. The cyclic activation, repression and reactivation of $\mathrm{frq}$ expression generate the endogenous circadian rhythmicity, which then controls the rhythmic expression of clockcontrolled genes.

WC-1 and WC-2, the positive elements in Neurospora circadian negative feedback loop, form heteromeric WC complexes mediated by the PASC domain of WC-1 and the single PAS domain of WC-2 (Talora et al., 1999; Cheng et al., 2002; Cheng et al., 2003a). wc-1 gene comprises three promoters: Pdist, Pprox and Pint (Káldi et al., 2006). Likewise, wc-2 gene contains several transcription initiation sites, which result in the expression of full-length WC-2 and sWC-2 in antagonistic manner (Neiss et al., 2008). In constant darkness, WCC rhythmically binds to the C-box which contains two GATN repeats on frq and ccgs promoters and activates their transcription (Froehlich et al., 2003; He et al., 2005a; He and Liu, 2005b; Belden et al., 2007b). Disruption of wc genes results in very low frq mRNA level and complete abolishment of circadian rhythmicity (Crosthwaite et al., 1997; Cheng et al., 2002, 2003a).

In addition to the role in repressing the WCC function in the negative feedback loop, $F R Q$ functions to promote the level of WC proteins ( Lee et al., 2000; Cheng et al., 2001b; Brunner and Schafmeier, 2006; Diernfellner et al., 2007). FRQ supports the accumulation of WC-1 at post-translational level and activates transcription of $w c-2$. WC proteins also regulate their expression and form another interconnected feedback loop. WC-1 indirectly inhibits $w c-2$ by controlling expression of a putative repressor, while in the presence of WC-1 and FRQ, it activates wc-2 transcription (Cheng et al., 2001b, 2003b). Like $F R Q, F R H$ is also required for these positive feedback loops (Cheng et al., 2005; Shi et al., 2009; Guo et al., 2010). These interconnected feedback loops are critical for maintaining the robust and stable clock function (Cheng et al., 2001a). Similar interlocked positive loops operate in mammalian and insect circadian systems (Glossop et al., 1999; Shearman et al., 2000).
In addition to its essential role in the circadian negative feedback loop, WC-1 also acts as blue-light receptor required for resetting and entrainment of the clock and almost all known light response in Neurospora (Froehlich et al., 2002; He et al., 2002, 2005b; Heintzen and Liu, 2007). Light induces rapid binding of the WCC to the promoters of frq and other light-induced genes (He et al., 2005b; Belden et al., 2007b).

Like other eukaryotic circadian oscillators, the Neurospora circadian oscillator is limit cycle-based. In Neurospora, temperature and light treatments can result in abolishment of the rhythmicity, a phenomenon called singularity behavior (Gooch et al., 1994; Huang et al., 2006). Both temperature step-up and a brief light exposure can trigger singularity (Huang et al., 2006). In addition, the change of FRQ level alone is sufficient to trigger the singularity behavior, indicating that FRQ is a state variable of the Neurospora limit cycle-based circadian clock. Furthermore, our results suggest that the singularity behavior is due to loss of the rhythms in all cells, after which cell population become desynchronized (Gooch et al., 1994; Huang et al., 2006).

\section{POST-TRANSLATIONAL REGULATION OF THE NEUROSPORA CLOCK}

\section{Phosphorylation of FRQ}

Phosphorylation of $F R Q$ is essential for its clock function (Cha et al., 2007). Studies in the last decade have led to the understanding of function of $F R Q$ phosphorylation and identification of many $\mathrm{FRQ}$ kinases and phosphotases (Table 1).

Like the animal PERIOD (PER) proteins, FRQ is progressively phosphorylated after its synthesis and becomes extensively phosphorylated before its degradation (Garceau et al., 1997). FRQ exists as many isoforms, with molecular sizes ranging from $\sim 120 \mathrm{kDa}$ to $\sim 200 \mathrm{kDa}$ result from the phosphorylation on different sites (Baker et al., 2009; Tang et al., 2009). In total, over $75 \mathrm{FRQ}$ phosphorylated residues have been identified (Baker et al., 2009; Tang et al., 2009). Except for a few regions, most of the $F R Q$ regions are phosphorylated, suggesting that FRQ adapts a non-globular 3D structure to allow most of protein to be accessible by kinases. Systematic mutagenesis of these phosphorylation sites demonstrated that multiple independent phosphorylation events along the FRQ ORF modulate the period of the clock by regulating $F R Q$ stability. While most of the phosphorylation events promote $F R Q$ degradation, the phosphorylation events near the C-terminal end stabilize $F R Q$, indicating that $F R Q$ stability is a major determinant in circadian period length and phosphorylation can play opposing roles to fine-tune $F R Q$ stability (Tang et al., 2009).

Five kinases, CK-1a (casein kinase-1a), CKII, CAMK-1 (calmodulin kinase 1), PKA and PRD-4 (chk2), have been shown to be FRQ kinases (Garceau et al., 1997; Görl et al., 
Table 1 Protein kinases and phosphotases in the Neurospora circadian clock

\begin{tabular}{|c|c|c|c|}
\hline enzymes & substrates & molecular functions in clock & clock phenotypes of mutants \\
\hline \multicolumn{4}{|l|}{ protein kinases } \\
\hline casein kinase I (CK-1) & FRQ; WC-1; WC-2 & $\begin{array}{l}\text { a major FRQ kinasealso mediates FRQ-dependent } \\
\text { WC phosphorylation; regulates the abundance of WCs }\end{array}$ & $c k-1 a^{L}$ exhibit $>30$ h periodicity \\
\hline casein kinase II (CK-2) & FRQ; WC proteins ${ }^{a}$ & $\begin{array}{l}\text { a major } F R Q \text { and } W C \text { kinase; stabilizes } F R Q ; \\
\text { represses the association between } F R Q \text { and } W C C\end{array}$ & $\begin{array}{l}\text { arrhythmic and low amplitude } \\
\text { long period rhythms }\end{array}$ \\
\hline $\begin{array}{l}\text { calmodulin kinase I } \\
\text { (CAMK-1) }\end{array}$ & $\mathrm{FRQ}$ & phosphorylates FRQ & $\begin{array}{l}\text { regulates the phase, period, and } \\
\text { light-induced phase shifting of the } \\
\text { conidiation rhythm }\end{array}$ \\
\hline $\begin{array}{l}\text { cyclic AMP-dependent } \\
\text { protein kinase A (PKA) }\end{array}$ & FRQ; WC proteins ${ }^{a}$ & $\begin{array}{l}\text { phosphorylates and stabilizes FRQ; phosphorylates } \\
\text { WCs and inhibits WCC activity; inhibits WC nuclear } \\
\text { localization }\end{array}$ & $\begin{array}{l}\text { arrhythmicity (mcb mutant) or low } \\
\text { amplitude rhythms (pkac-1 mutant) }\end{array}$ \\
\hline protein kinase $\mathrm{C}(\mathrm{PKC})$ & WC-1 & WC-1; decreases WC-1 level & regulates light response \\
\hline $\begin{array}{l}\text { checkpoint kinase } 2 \\
\text { (chk2/PRD-4) }\end{array}$ & $\mathrm{FRQ}$ & phosphorylates FRQ & resets clock upon DNA damage \\
\hline \multicolumn{4}{|l|}{ protein phosphotases } \\
\hline $\begin{array}{l}\text { protein phosphotase } 1 \\
\text { (PP1) }\end{array}$ & $\mathrm{FRQ}$ & dephosphorylates and stabilizes FRQ & $\begin{array}{l}\text { regulates phase; exhibits } \\
\text { short period rhythms }\end{array}$ \\
\hline $\begin{array}{l}\text { protein phosphotase } 2 \mathrm{~A} \\
(\mathrm{PP} 2 \mathrm{~A})\end{array}$ & FRQ; WC proteins ${ }^{a}$ & dephosphorylates FRQ and WCs & $\begin{array}{l}\text { regulates period and amplitude } \\
\text { of the rhythms }\end{array}$ \\
\hline $\begin{array}{l}\text { protein phosphotase } 4 \\
\text { (PP4) }\end{array}$ & $F R Q^{a}$ & $\begin{array}{l}\text { dephosphorylates FRQ and WCs; } \\
\text { promotes nuclear entry of WCC }\end{array}$ & $\begin{array}{l}\text { regulates period and amplitude } \\
\text { of the rhythms }\end{array}$ \\
\hline
\end{tabular}

a The relevant enzymes regulate both WC-1 and WC-2.

2001; Yang et al., 2001, 2002, 2003; He et al., 2006; Pregueiro et al., 2006; Huang et al., 2007) (Table 1). Among these kinases, CK-1a and CKII contribute to most of the FRQ phosphorylation events (Yang et al., 2004; He et al., 2006; Tang et al., 2009). On the other hand, it has been shown that PRD-4 (chk2) mediates FRQ phosphorylation after DNA damage, while CAMK-1 affects the light entrainment of the clock (Yang et al., 2001; Pregueiro et al., 2006).

The Drosophila DOUBLETIME (DBT) and the mammalian CKI homologs, including CKI $\delta$ as well as $\mathrm{CKl} \varepsilon$, associates with and phosphorylates animal PER proteins (Kloss et al., 1998; Price et al., 1998; Lowrey and Takahashi, 2000; Xu et al., 2005). Similarly, CK-1a was found to be tightly associated with FRQ (Yang et al., 2003; Baker et al., 2009; Mehra et al., 2009b). A ck-1a mutant, which contains the same mutation as the Drosophila $d b t^{L}$, exhibits hypophosphorylated $\mathrm{FRQ}$ and more than $30 \mathrm{~h}$ period due to increased $\mathrm{FRQ}$ stability (He et al., 2006). In addition, CK-1a mediates the FRQ-depedent phosphorylation of WC-1 and WC-2 which inhibits the WCC activity to close the negative feedback loop (He et al., 2006; Querfurth et al., 2007). Although another Neurospora CK-1 homolog CK1-b can phosphorylate FRQ in vitro, the disruption of $c k-1 b$ gene resulted in no significant change in both $F R Q$ phosphorylation and oscillation of $F R Q$, suggesting it's not essential for the clock functions (Yang et al., 2003).

Protein kinase CKII, also termed casein kinase-2, is a ubiquitous protein kinase consisting of two catalytic ( $\alpha$ and/or $\left.\alpha^{\prime}\right)$ subunits and two regulatory subunits. Like CKI, CKII exhibits conserved function in circadian clock functions in plant, fungi, as well as animal (Yang et al., 2002; Allada and Meissner, 2005). In Neurospora CKII was biochemically purified as a major FRQ kinase (Yang et al., 2002). In a mutant, in which the catalytic subunit of CKII (cka) was disrupted, FRQ protein is hypophosphorylated and stabilized, and the circadian rhythms are completely abolished (Yang et al. 2002). Similarly, the disruption of $c k b 1$, the gene encoding for the regulatory subunit, led to hypophosphorylation and stabilization of FRQ as well as and long periods but low amplitude oscillations (Yang et al., 2002, 2003).

The Neurospora CKII also regulates the temperature compensation of circadian clock (Mehra et al., 2009b). Temperature compensation is one of the several hallmarks of circadian clocks, which allows circadian clocks to function precisely at different temperatures. Reduction of CKII resulted in changes of temperature compensation in a dosage dependent manner. In the chrono and prd3 mutants which bore a mutation in ckb1 and cka subunits, respectively, the temperature compensation was partially impaired (Mehra et al., 2009b).

The eukaryotic PKA (cyclic AMP-dependent protein kinase A) holoenzyme consists of catalytic subunits and inhibitory regulatory subunits. The binding of cyclic AMP (cAMP) to the regulatory subunit of PKA results in its activation (Taylor et al., 
2005). Mutants of both of the PKA catalytic (pkac-1) and regulatory $(m c b)$ subunit genes exhibit loss of circadian rhythms and altered expression levels of $F R Q$ and WC proteins (Huang et al., 2007). PKA mediates the phosphorylation of both $F R Q$ and WC proteins. The phosphorylation of $F R Q$ by $P K A$ results in stabilization of $F R Q$, which is in contrast to the function of the casein kinases (Huang et al., 2007). A similar role of phosphorylation in stabilization of clock proteins was also seen with the phosphorylation of the FASP site in mammals (Vanselow et al., 2006; Huang et al., 2007; Xu et al., 2007). Thus, phosphorylation of clock proteins at different sites can play opposite roles in regulating $F R Q$ stability. It is possible that the phosphorylation by PKA at certain sites of $F R Q$ can inhibit the efficient ubiquitilation or phosphorylation of $F R Q$.

In addition to these kinases, FRH can also indirectly regulate the phosphorylation profile of $F R Q$. In the frh knockdown strain and those strains in which the FRH-FRQ interaction was abolished, FRQ becomes hypophosphorylated and the amount of $F R Q$ is dramatically reduced due to rapid degradation (Guo et al., 2010). It is likely that FRH can regulate the protein-protein associations between $F R Q$ and its kinases.

\section{FRQ inhibits WCC activity by promoting WC phosphorylation}

Phosphorylation of WC proteins is essential for the negative feedback loop process in Neurospora (Lauter and Russo, 1990; Schafmeier et al., 2005; He et al., 2005b, 2006). Several kinases have been demonstrated to mediate the phosphorylation of WC proteins. These kinases include CKI, CKII, PKA and PKC (Table 1) (Yang et al., 2001, 2002, 2003; Franchi et al., 2005; He et al., 2006; Huang et al., 2007; Querfurth et al., 2007). WC proteins are phosphorylated in constant darkness and hyperphosphorylated in the light $(\mathrm{He}$ et al., 2005b). Hypophosphorylated WCC becomes active for the transcription of frq and ccg genes while hyperphosphorylated WCC is inactive (Bell-Pedersen et al., 1996; Crosthwaite et al., 1997; Cha et al., 2008; Schafmeier et al., 2008). Phosphorylation of WC proteins inhibits its DNA binding activity in vitro and in vivo and both WC-1 and WC2 are hypophosphorylated in the frq null strain, suggesting that FRQ inhibits WCC activity by promoting the phosphorylation of WC proteins (He and Liu, 2005b; He et al., 2005b; Schafmeier et al., 2005; Hong et al., 2008). The inhibition of WCC transcriptional activity by FRQ-dependent phosphorylation closes the circadian negative feedback loop.

FRQ recruits both CK-1a and CKII to mediate FRQdependent WC phosphorylation and inhibition ( $\mathrm{He}$ et al., 2006). In FRQ mutants which the FRQ-CK-1a interaction is disrupted, both WCs become hypophosphorylated. In addition, both WC-1 and WC-2 are also hypophosphorylated in ck1-a and cka (catalytic subunit of CKII) mutants, and WCC constitutively binds to the frq promoter at high levels (He et al., 2006). These results indicate the importance of $F R Q, C K-1 a$ and CKII in closing the circadian negative feedback loop.

There are five major in vivo WC-1 phosphorylation sites which are located immediately downstream of the DNA binding domain (Ser-988, Ser-990, Ser-992, Ser-994, and Ser-995), which are critical for the clock function of WC-1 (He et al., 2005b). Quantitative mass spectrometry analyses revealed that phosphorylation of these sites is a sequential process: first by FRQ-independent phosphroylation at Ser990 by a priming kinase and then by $F R Q$-dependent phosphorylation events at the other sites (Huang et al., 2007). PKA acts as the priming kinase that phosphorylates on S990 of WC-1, which converts the rest of the serine sites into good CK1 or CKII sites (Huang et al., 2007). In pkac- ${ }^{\text {ko }}$ (the catalytic subunit of PKA) strain, WC-1 and WC-2 are hypophosphorylated and the levels are extremely low. In addition, the frq $\mathrm{mRNA}$ levels are high despite low WC levels in this mutant. In contrast, although WC levels are high, frq mRNA levels are very low in the mcb mutants (the regulatory subunit of PKA). Together, these results demonstrate that PKA phosphorylates and inhibits WCC activity (Huang et al., 2007). Similarly, hPER2 was shown to be sequentially phosphorylated near the FASPS site by CK1 and an unidentified priming kinase (Vanselow et al., 2006; Xu et al., 2007).

\section{Dephosphorylation of clock proteins}

Phosphorylation of FRQ and WC proteins is reversibly regulated by several phosphotases. So far, phosphotase 1 (PP1), phosphotase 2A (PP2A) and phosphotase 4 (PP4) have been identified as clock-related phosphatases in Neurospora (Yang et al., 2004; Cha et al., 2008) (Table 1).

PP1 and PP4 antagonize the functions of the casein kinaseson FRQ by protein stabilization. In both $p p p-1$ and $p p 4$ (catalytic subunits of PP1 and PP4, respectively) mutants FRQ protein is less stable, resulting in advanced phase and short period phenotypes (Yang et al., 2004; Cha et al., 2008).

in vitro experiments suggest that $F R Q$ is a substrate for both PP1 and PP2A (Yang et al., 2004). The mutation in rgb-1 (the regulatory subunit of PP2A) resulted in low abundance of both frq mRNA and FRQ protein (Yang et al., 2004), indicating its essential role in the circadian negative feedback loop. One circadian role of PP2A is achieved by its dephosphorylation and reactivation of WC proteins (Yang et al., 2004; Schafmeier et al., 2005). In the rgb-1 mutant, WC-2 is hyperphosphorylated, consistent with low WCC activity. In addition to its role in dephosphorylating FRQ, PP4 also dephosphorylates WC proteins and activates their activity by promoting the nuclear entry of WCC (Cha et al., 2008). Together, these results suggest that these phosphotases play important but distinct roles in the Neurospora circadian clock by acting on different clock proteins or on different phosphorylation sites. Similarly, both PP1 and PP2A have been shown 
to play similar roles in Drosophila and mammalian circadian clocks (Cohen, 2002; Sathyanarayanan et al., 2004; Fang et al., 2007).

\section{Regulation of cellular localization of FRQ and WC proteins}

Translocation of FRQ

FRQ contains a functional nuclear localization signal (195-200 aa) and mutation of which causes loss of the circadian rhythmicity (Luo et al., 1998). However, the majority of $\mathrm{FRQ}$ protein ( $>90 \%$ ) is present in the cytoplasm (Cheng et al., 2005; Schafmeier et al., 2005). The loss of circadian rhythm by elimination of FRQ NLS suggests that nuclear $F R Q$ is essential for its clock function (Luo et al., 1998; Diernfellner et al., 2009). Shortly after its synthesis, FRQ enters the nucleus to fulfill its function both in the negative feedback loop to repress the WCC activity and in the positive limb to promote the WC proteins level (Luo et al., 1998; Cheng et al., 2001b; Diernfellner et al., 2009). FRQ shuttles rapidly between the nucleus and cytoplasm and its phosphorylation appears to regulate its nucleocytoplasmic shuttling (Diernfellner et al., 2009). Hypophosphorylated $F R Q$ enters the nuclei more efficiently while the nuclear import efficiency of hyperphosphorylated FRQ is low. In contrast to the role of nucleic $F R Q$ in closing the negative feedback loop of clock, the function of the cytoplasmic FRQ remains elusive. The association between $F R Q, F R H$ and the exosome components suggests a potent function of the cytoplasmic FFC complex in the circadian regulation of RNA metabolism (Guo et al., 2009).

\section{Translocation of WC proteins}

Like $F R Q$, nucleocytoplasmic shuttling of WC proteins is regulated by phosphoryation, which is critical for their clock function. The nucleocytoplasmic shuttling of WC proteins is regulated by their phosphorylation states. Hypophosphorylated WCC is enriched in nuclei which functions to bind DNA and activate the transcription of the target genes including fra and ccgs (Cha et al., 2008; Hong et al., 2008; Schafmeier et al., 2008; Diernfellner et al., 2009). In contrast, hyperphosphorylation of WCC results in low abundance of nuclear WCs.

PKA and PP4 have been demonstrated to be regulators in modulating the nucleocytoplasmic shuttling of WC proteins (Cha et al., 2008). PP4 functions to promote the nuclear entry of WCC while PKA inhibits WC nuclear localization. In addition, FRQ plays a role in mediating WCs nucleocytoplasmic shuttling by regulating the phosphorylation and abundance of WCs. It's been proposed that the accumulation of cytoplasmic FRQ recruits kinases to phosphorylate WCC and inhibit its nuclear entry (Cha et al., 2008; Hong et al., 2008; Schafmeier et al., 2008; Diernfellner et al., 2009).

\section{REGULATION OF FRQ DEGRADATION}

FRQ protein undergoes progressive phosphorylation that leads to its eventual degradation, and this turnover process is essential in maintaining the circadian cycles and is a major determinant in circadian period length (Liu et al., 2000; He et al., 2003, 2005a; Baker et al., 2009; Mehra et al., 2009a; Tang et al., 2009). This phosphorylation-dependent turnover process is controlled by the ubiquitin/proteasome pathway, which is conserved in eukaryotic clocks ( $\mathrm{He}$ et al. 2003; He and Liu, 2005a; Mehra et al., 2009a).

In $c k-1 a$ and cka mutants, FRQ was hypophosphorylated and more stable which indicating that a major role of $F R Q$ phosphorylation by CK-1a and CKII is to promote $\mathrm{FRQ}$ degradation (Yang et al., 2002, 2003, He et al., 2006). On the other hand, PP1 and PP4 dephosphorylate and stabilize FRQ to oppose the effects of the casein kinases (Yang et al., 2004; Cha et al., 2008). Overall, the combined effects of these kinases and phosphatases set the phosphorylation state and stability of $F R Q$.

The phosphorylation-dependent FRQ degradation by the ubiquitin/proteasome pathway is mediated an SCF (Skp1/ Cullin/F-box protein) ubiquitin ligase (E3), in which the F-box/ WD40-repeat-containing protein FWD-1 is the substraterecruiting subunit (He et al. 2003). Disruption of fwd-1 results in hyperphosphorylation of $F R Q$, high $F R Q$ levels and circadian arrhythimicity. The high level of FRQ in the mutant is due to blocked degradation. In addition, FWD-1 bound tightly with $F R Q$ when the F-box of FWD-1 is deleted. On the other hand, the FRQ-FWD-1 interaction was not detected in a wild-type strain, indicating that the tight FRQ-FWD-1 association results in rapid $F R Q$ ubiquitination and degradation. The FWD-1 homologs in Drosophila (Slimb) and mammals (beta-TRCPs) are also components of SCF ubiquitin ligases that mediate the phosphorylation-dependent degradation of PER proteins (Grima et al., 2002; Ko et al., 2002; He et al., 2003; Eide et al., 2005; Shirogane et al., 2005).

The study of the circadian functions of the COP9 signalosome (CSN) in Neurospora further confirmed that the importance of the ubiquitin-mediated $F R Q$ degradation (He et al., 2005a). The CSN is a conserved deneddylation complex in eukaryotes, which contains eight distinct subunits (from CSN1 to CSN8) (Cope and Deshaies, 2003; He et al., 2005a). In Neurospora, the CSN plays a role in modulating the clock by regulating the stability of the $\mathrm{SCF}^{\mathrm{FWD}-1}$ complex (He et al., 2005a; Cha et al., 2007). Disruption of the essential CSN component csn-2 hindered the FRQ degradation and severely impaired circadian rhythmicity due to extremely low FWD-1 levels. The low FWD-1 levels in the csn-2 mutant was caused by increased auto-ubiquitination of the SCF complex (He et al., 2005a).

The mammalian FWD-1 homolog beta-TRCPs recognize a high affinity DpSG $\Phi$ XpS motif on their substrates (Wu et al., 2003). Like mammalian PERs, FRQ lacks such a motif. The 
involvement of multiple independent phosphorylation events in $F R Q$ degradation suggests that FWD-1 does not recognize FRQ by a single high affinity site (Baker et al., 2009; Tang et al. 2009). Instead, we propose that there are multiple suboptimal FWD-1 binding sites on FRQ and the phosphorylation of $F R Q$ at multiple sites can progressively promote the interaction between FRQ and FWD-1. Thus, extensive FRQ phosphorylation leads to tight FRQ-FWD-1association and rapid $F R Q$ ubiquitination and degradation (Tang et al., 2009).

Our recent study also suggests an alternative pathway for FRQ degradation that is independent of FWD-1. When frh is silenced or when the interaction between FRH and FRQ is abolished, FRQ protein becomes hypophosphorylated and undergoes rapid degradation. Such an effect of $F R H$ on $F R Q$ phosphorylation and stability is independent of FWD-1 since the knock-down of frh in the fwd-1 mutant also results in rapid degradation of $F R Q$, indicating the existence of an alternative FRQ degradation pathway (Guo et al., 2010). Since FRH is necessary for the maintenance of $F R Q$ phosphorylation status and stability, it is likely that the proper protein conformation of FRQ is critical for its stability and function.

\section{POST-TRANSCRIPTIONAL REGULATION OF THE NEUROSPORA CLOCK}

In addition to the transcriptional and post-translational mechanisms that control the Neurospora clock, regulation at the post-transcriptional levels also plays important role. The frq gene locus transcribes multiple endogenous non-coding antisense transcripts qrfs. The expression of qrf cycles is in anti-phase manner to that of the sense frq transcripts (Kramer et al., 2003; Tralau et al., 2007). The expression of the qrfs was shown to contribute to the light entrainment of the clock by regulating frq expression.

FRQ and FRH form the FFC complex that represses frq mRNA levels. FRH is a homolog of Mtr4p in Saccharomyces cerevisiae, which is an essential nuclear co-factor for the exosome complex, a large complex consisting of several $3^{\prime} \rightarrow$ $5^{\prime}$ exonucleases important for RNA metabolism by mediating $3^{\prime} \rightarrow 5^{\prime}$ processing and degradation (LaCava et al., 2005; Vanácováet al., 2005; Houseley et al., 2006). Our recent results suggest that FFC and exosome are involved in a posttranscriptional negative feedback loop that is interlocked with the transcriptional loop (Guo et al., 2009).

In this post-transcriptional loop, FRQ promotes frq RNA decay and the level of FRQ determines frq RNA stability, resulting in a daily rhythm of frq RNA stability. frq RNA is more stable in the $\mathrm{frq}^{9}$ strain and at a time point when FRQ level is low. In addition, the silencing of $\mathrm{FRH}$ resulted in abnormally high frq RNA level due to impaired RNA degradation. Furthermore, FRQ was shown to associate with fra RNA specifically and with the core exosome component RRP44 (rRNA processing 44). Finally, the downregulation of RRP44, the catalytic subunit of the exosome, resulted in an increase of frq RNA and severe impairment of the circadian rhythmicities. These results suggest that FFC and exosome are part of a post-transcriptional negative feedback loop that regulates frq RNA level. Therefore, both the transcriptional and the post-transcriptional processes mediated by FFC contribute to the circadian negative feedback loop process (Guo et al., 2009). In this scenario, when FRQ levels are high, frq mRNA levels are decreased by both the inhibition of the WCC activity and rapid degradation of frq RNA. When FRQ levels are low, frq mRNA levels increase rapidly due to WCC activation and increased frq RNA stability.

The mRNA of rrp44 is also a clock-controlled gene with a phase that is very similar to frq (Guo et al., 2009). The levels of rrp44 are reduced in wc mutants and WCC was shown to bind to the promoter of rrp44 rhythmically. These results demonstrate that like frq, the expression of $r r p 44$ is directly controlled by WCC. In addition to its role regulating frq RNA degradation, RRP44 also control the expression levels of a sub-set of ccgs, suggesting that the rhythmical activity of the exosome also plays an important role in regulating the circadian output pathways by controlling mRNA decay (Guo et al., 2009).

In mammals and Drosophila, NONO is a RNA/DNA binding protein that binds to clock protein PER1. Silencing of NONO led to abolishment of rhythmicity (Brown et al., 2005). Whether NONO regulates the clock in a post-transcriptional manner remains to be demonstrated.

\section{EPIGENETIC REGULATION OF THE NEUROSPORA CLOCK}

Epigenetic mechanism plays an important role in regulating eukaryotic gene expression. Mounting evidence has suggested that various chromatin modifications are important for eukaryotic circadian clock functions. In eukaryotes, acetylation of histones $\mathrm{H} 3$ and $\mathrm{H} 4$ promotes the promoter accessibility for transcription. In Neurospora and mammals, it has been shown that the histone acetylation is controlled in a circadian manner (Etchegaray et al., 2003; Belden et al., 2007b). By screening of the ATP-dependent chromatinremodeling enzymes in Neurospora, csw-1 (clockswitch 1), one of homologs to yeast genes Sth2 and $m i-2$, was identified to be important for clock function (Belden et al., 2007a). The loss of csw-1 resulted in sporadic conidiation as well as impaired circadian rhythms (Belden et al., 2007b). Even though CSW-1 is not rhythmically expressed, it may binds to frq promoter to facilitate the rhythmic binding of WCC.

\section{CONCLUSIONS AND PERSPECTIVES}

The filamentous fungus Neurospora is one of the best understood circadian model systems for clock research due to its durability and simplicity. The understanding of the molecular of the Neurospora circadian clock has contributed significantly to how eukaryotic clocks work in general. The 
basic circadian mechanisms share remarkable similarities and conservations between Neurospora and animal circadian oscillators. Despite of our current understanding the Neurospora circadian oscillator, many important questions remain. These questions include the mechanism that controls of $F R Q$ and WC cellular localization, mechanism of temperature compensation of the clock, the roles of post-transcriptional regulation in the control of circadian rhythms, and roles of non-frq based oscillators in the clock, etc. In the future, studies using Neurospora will lead to the revelation of new regulatory mechanisms at different levels and Neurospora will continue to serve as a premier eukaryotic model system for clock research.

\section{ACKNOWLEDGEMENTS}

This work was supported by grants from National Institutes of Health (Grant Nos. GM062591 and GM068496 to Y.L.) and Welch Foundation (to Y.L.). Y.L. is the Louise W. Kahn endowed scholar in Biomedical Research at University of Texas South-western Medical Center.

\section{ABBREVIATIONS}

CAMK-1, calmodulin kinase 1; cAMP, cyclic AMP; ccgs, clockcontrolled genes; CK-1a, casein kinase-1a; CSN, COP9 signalosome; csw-1, clockswitch 1; DBT, DOUBLETIME; FFC, FRQ-FRH complex; FRH, FRQ-INTERACTING RNA HELICASE; FRQ, FREQUENCY; IFRQ, large FRQ; NATs, natural antisense transcripts; PAS, PER-ARNT-SIM; PER, PERIOD; PKA, cyclic AMP-dependent protein kinase A; PP1, phosphotase 1; PP2A, phosphotase 2A; PP4, phosphotase 4; RRP44, rRNA processing 44; SCF, Skp1/Cullin/Fbox protein; sFRQ, smallFRQ; WCC, WC complex; WC-1, WHITE COLLAR 1; WC-2, WHITE COLLAR 2

\section{REFERENCES}

Allada, R., and Meissner, R.A. (2005). Casein kinase 2, circadian clocks, and the flight from mutagenic light. Mol Cell Biochem 274, 141-149.

Aronson, B.D., Johnson, K.A., and Dunlap, J.C. (1994a). Circadian clock locus frequency: protein encoded by a single open reading frame defines period length and temperature compensation. Proc Natl Acad Sci U S A 91, 7683-7687.

Aronson, B.D., Johnson, K.A., Loros, J.J., and Dunlap, J.C. (1994b). Negative feedback defining a circadian clock: autoregulation of the clock gene frequency. Science 263, 1578-1584.

Baker, C.L., Kettenbach, A.N., Loros, J.J., Gerber, S.A., and Dunlap, J.C. (2009). Quantitative proteomics reveals a dynamic interactome and phase-specific phosphorylation in the Neurospora circadian clock. Mol Cell 34, 354-363.

Ballario, P., Vittorioso, P., Magrelli, A., Talora, C., Cabibbo, A., and Macino, G. (1996). White collar-1, a central regulator of blue light responses in Neurospora, is a zinc finger protein. EMBO $\mathrm{J} 15$, 1650-1657.

Belden, W.J., Larrondo, L.F., Froehlich, A.C., Shi, M., Chen, C.H., Loros, J.J., and Dunlap, J.C. (2007a). The band mutation in
Neurospora crassa is a dominant allele of ras-1 implicating RAS signaling in circadian output. Genes Dev 21, 1494-1505.

Belden, W.J., Loros, J.J., and Dunlap, J.C. (2007b). Execution of the circadian negative feedback loop in Neurospora requires the ATPdependent chromatin-remodeling enzyme CLOCKSWITCH. Mol Cell 25, 587-600.

Bell-Pedersen, D., Dunlap, J.C., and Loros, J.J. (1996). Distinct cisacting elements mediate clock, light, and developmental regulation of the Neurospora crassa eas (ccg-2) gene. Mol Cell Biol 16, 513-521.

Bell-Pedersen, D., Cassone, V.M., Earnest, D.J., Golden, S.S., Hardin, P.E., Thomas, T.L., and Zoran, M.J. (2005). Circadian rhythms from multiple oscillators: lessons from diverse organisms. Nat Rev Genet 6, 544-556.

Brown, S.A., Ripperger, J., Kadener, S., Fleury-Olela, F., Vilbois, F., Rosbash, M., and Schibler, U. (2005). PERIOD1-associated proteins modulate the negative limb of the mammalian circadian oscillator. Science 308, 693-696.

Brunner, M., and Schafmeier, T. (2006). Transcriptional and posttranscriptional regulation of the circadian clock of cyanobacteria and Neurospora. Genes Dev 20, 1061-1074.

Cha, J., Huang, G., Guo, J., and Liu, Y. (2007). Posttranslational control of the Neurospora circadian clock. Cold Spring Harb Symp Quant Biol 72, 185-191.

Cha, J., Chang, S.S., Huang, G., Cheng, P., and Liu, Y. (2008). Control of WHITE COLLAR localization by phosphorylation is a critical step in the circadian negative feedback process. EMBO $\mathrm{J}$ 27, 3246-3255.

Cheng, P., Yang, Y., Heintzen, C., and Liu, Y. (2001a). Coiled-coil domain-mediated $F R Q-F R Q$ interaction is essential for its circadian clock function in Neurospora. EMBO J 20, 101-108.

Cheng, P., Yang, Y., and Liu, Y. (2001b). Interlocked feedback loops contribute to the robustness of the Neurospora circadian clock. Proc Natl Acad Sci U S A 98, 7408-7413.

Cheng, P., Yang,Y., Gardner, K.H., and Liu, Y. (2002). PAS domainmediated WC-1/WC-2 interaction is essential for maintaining the steady-state level of WC-1 and the function of both proteins in circadian clock and light responses of Neurospora. Mol Cell Biol 22, 517-524.

Cheng, P., He, Q., Yang, Y., Wang, L., and Liu, Y. (2003a). Functional conservation of light, oxygen, or voltage domains in light sensing. Proc Natl Acad Sci U S A 100, 5938-5943.

Cheng, P., Yang, Y., Wang, L., He, Q., and Liu, Y. (2003b). WHITE COLLAR-1, a multifunctional Neurospora protein involved in the circadian feedback loops, light sensing, and transcription repression of wc-2. J Biol Chem 278, 3801-3808.

Cheng, P., He, Q., He, Q., Wang, L., and Liu, Y. (2005). Regulation of the Neurospora circadian clock by an RNA helicase. Genes Dev 19, 234-241.

Cohen, P.T. (2002). Protein phosphatase 1-targeted in many directions. J Cell Sci 115, 241-256.

Colot, H.V., Loros, J.J., and Dunlap, J.C. (2005). Temperaturemodulated alternative splicing and promoter use in the Circadian clock gene frequency. Mol Biol Cell 16, 5563-5571.

Cope, G.A., and Deshaies, R.J. (2003). COP9 signalosome: a multifunctional regulator of SCF and other cullin-based ubiquitin ligases. Cell 114, 663-671.

Crosthwaite, S.K., Dunlap, J.C., and Loros, J.J. (1997). Neurospora 
wc-1 and wc-2: transcription, photoresponses, and the origins of circadian rhythmicity. Science 276, 763-769.

de Paula, R.M., Lamb, T.M., Bennett, L., and Bell-Pedersen, D. (2008). A connection between MAPK pathways and circadian clocks. Cell Cycle 7, 2630-2634.

Diernfellner, A., Colot, H.V., Dintsis, O., Loros, J.J., Dunlap, J.C., and Brunner, M. (2007). Long and short isoforms of Neurospora clock protein $F R Q$ support temperature-compensated circadian rhythms. FEBS Lett 581, 5759-5764.

Diernfellner, A.C., Querfurth, C., Salazar, C., Höfer, T., and Brunner, M. (2009). Phosphorylation modulates rapid nucleocytoplasmic shuttling and cytoplasmic accumulation of Neurospora clock protein FRQ on a circadian time scale. Genes Dev 23, 2192-2200.

Dunlap, J.C., and Loros, J.J. (2004). The neurospora circadian system. J Biol Rhythms 19, 414-424.

Dunlap, J.C., Loros, J.J., Colot, H.V., Mehra, A., Belden, W.J., Shi, M., Hong, C.I., Larrondo, L.F., Baker, C.L., Chen, C.H., et al. (2007). A circadian clock in Neurospora: how genes and proteins cooperate to produce a sustained, entrainable, and compensated biological oscillator with a period of about a day. Cold Spring Harb Symp Quant Biol 72, 57-68.

Eide, E.J., Woolf, M.F., Kang, H., Woolf, P., Hurst, W., Camacho, F., Vielhaber, E.L., Giovanni, A., and Virshup, D.M. (2005). Control of mammalian circadian rhythm by CKlepsilon-regulated proteasome-mediated PER2 degradation. Mol Cell Biol 25, 2795-2807.

Etchegaray, J.P., Lee, C., Wade, P.A., and Reppert, S.M. (2003). Rhythmic histone acetylation underlies transcription in the mammalian circadian clock. Nature 421, 177-182.

Fang, Y., Sathyanarayanan, S., and Sehgal, A. (2007). Posttranslational regulation of the Drosophila circadian clock requires protein phosphatase 1 (PP1). Genes Dev 21, 1506-1518.

Foster, R.G. (2004). Seeing the light...in a new way. J Neuroendocrinol 16, 179-180.

Franchi, L., Fulci, V., and Macino, G. (2005). Protein kinase C modulates light responses in Neurospora by regulating the blue light photoreceptor WC-1. Mol Microbiol 56, 334-345.

Froehlich, A.C., Liu, Y., Loros, J.J., and Dunlap, J.C. (2002). White Collar-1, a circadian blue light photoreceptor, binding to the frequency promoter. Science 297, 815-819.

Froehlich, A.C., Loros, J.J., and Dunlap, J.C. (2003). Rhythmic binding of a WHITE COLLAR-containing complex to the frequency promoter is inhibited by FREQUENCY. Proc Natl Acad Sci U S A 100, 5914-5919.

Garceau, N.Y., Liu, Y., Loros, J.J., and Dunlap, J.C. (1997). Alternative initiation of translation and time-specific phosphorylation yield multiple forms of the essential clock protein FREQUENCY. Cell 89, 469-476.

Glossop, N.R., Lyons, L.C., and Hardin, P.E. (1999). Interlocked feedback loops within the Drosophila circadian oscillator. Science 286, 766-768.

Gooch, V.D., Wehseler, R.A., and Gross, C.G. (1994). Temperature effects on the resetting of the phase of the Neurospora circadian rhythm. J Biol Rhythms 9, 83-94.

Görl, M., Merrow, M., Huttner, B., Johnson, J., Roenneberg, T., and Brunner, M. (2001). A PEST-like element in FREQUENCY determines the length of the circadian period in Neurospora crassa. EMBO J 20, 7074-7084.

Grima, B., Lamouroux, A., Chélot, E., Papin, C., Limbourg-Bouchon,
B., and Rouyer, F. (2002). The F-box protein slimb controls the levels of clock proteins period and timeless. Nature 420, 178-182.

Guo, J., Cheng, P., Yuan, H., and Liu, Y. (2009). The exosome regulates circadian gene expression in a posttranscriptional negative feedback loop. Cell 138, 1236-1246.

Guo, J., Cheng, P., and Liu, Y. (2010). Functional significance of FRH in regulating the phosphorylation and stability of the neurospora circadian clock protein FRQ. J Biol Chem 285, 11508-11515.

Harmer, S.L. (2009). The circadian system in higher plants. Annu Rev Plant Biol 60, 357-377.

He, Q., and Liu, Y. (2005a). Degradation of the Neurospora circadian clock protein FREQUENCY through the ubiquitin-proteasome pathway. Biochem Soc Trans 33, 953-956.

$\mathrm{He}, \mathrm{Q}$., and Liu, Y. (2005b). Molecular mechanism of light responses in Neurospora: from light-induced transcription to photoadaptation. Genes Dev 19, 2888-2899.

He, Q., Cheng, P., Yang, Y., Wang, L., Gardner, K.H., and Liu, Y. (2002). White collar-1, a DNA binding transcription factor and a light sensor. Science 297, 840-843.

He, Q., Cheng, P., Yang, Y., He, Q., Yu, H., and Liu, Y. (2003). FWD1mediated degradation of FREQUENCY in Neurospora establishes a conserved mechanism for circadian clock regulation. EMBO J 22, 4421-4430.

He, Q., Cheng, P., He, Q., and Liu, Y. (2005a). The COP9 signalosome regulates the Neurospora circadian clock by controlling the stability of the SCFFWD-1 complex. Genes Dev 19, 1518-1531.

He, Q., Shu, H., Cheng, P., Chen, S., Wang, L., and Liu, Y. (2005b). Light-independent phosphorylation of WHITE COLLAR-1 regulates its function in the Neurospora circadian negative feedback loop. J Biol Chem 280, 17526-17532.

He, Q., Cha, J., He, Q., Lee, H.C., Yang, Y., and Liu, Y. (2006). CKI and CKII mediate the FREQUENCY-dependent phosphorylation of the WHITE COLLAR complex to close the Neurospora circadian negative feedback loop. Genes Dev 20, 2552-2565.

Heintzen, C., and Liu, Y. (2007). The Neurospora crassa circadian clock. Adv Genet 58, 25-66.

Hong, C.I., Ruoff, P., Loros, J.J., and Dunlap, J.C. (2008). Closing the circadian negative feedback loop: FRQ-dependent clearance of WC-1 from the nucleus. Genes Dev 22, 3196-3204.

Houseley, J., LaCava, J., and Tollervey, D. (2006). RNA-quality control by the exosome. Nat Rev Mol Cell Biol 7, 529-539.

Huang, G., Wang, L., and Liu, Y. (2006). Molecular mechanism of suppression of circadian rhythms by a critical stimulus. EMBO J 25, 5349-5357.

Huang, G., Chen, S., Li, S., Cha, J., Long, C., Li, L., He, Q., and Liu, Y. (2007). Protein kinase $A$ and casein kinases mediate sequential phosphorylation events in the circadian negative feedback loop. Genes Dev 21, 3283-3295.

Káldi, K., González, B.H., and Brunner, M. (2006). Transcriptional regulation of the Neurospora circadian clock gene wc-1 affects the phase of circadian output. EMBO Rep 7, 199-204.

Kloss, B., Price, J.L., Saez, L., Blau, J., Rothenfluh, A., Wesley, C.S., and Young, M.W. (1998). The Drosophila clock gene double-time encodes a protein closely related to human casein kinase lepsilon. Cell 94, 97-107.

Ko, H.W., Jiang, J., and Edery, I. (2002). Role for Slimb in the degradation of Drosophila Period protein phosphorylated by 
Doubletime. Nature 420, 673-678.

Kramer, C., Loros, J.J., Dunlap, J.C., and Crosthwaite, S.K. (2003). Role for antisense RNA in regulating circadian clock function in Neurospora crassa. Nature 421, 948-952.

LaCava, J., Houseley, J., Saveanu, C., Petfalski, E., Thompson, E., Jacquier, A., and Tollervey, D. (2005). RNA degradation by the exosome is promoted by a nuclear polyadenylation complex. Cell 121, 713-724.

Lauter, F.R., and Russo, V.E. (1990). Light-induced dephosphorylation of a $33 \mathrm{kDa}$ protein in the wild-type strain of Neurospora crassa: the regulatory mutants wc- 1 and wc- 2 are abnormal. J Photochem Photobiol B 5, 95-103.

Lee, K., Loros, J.J., and Dunlap, J.C. (2000). Interconnected feedback loops in the Neurospora circadian system. Science 289, 107-110.

Levine, J.D. (2004). Sharing time on the fly. Curr Opin Cell Biol 16, 210-216.

Linden, H., and Macino, G. (1997). White collar 2, a partner in bluelight signal transduction, controlling expression of light-regulated genes in Neurospora crassa. EMBO J 16, 98-109.

Liu, Y. (2003). Molecular mechanisms of entrainment in the Neurospora circadian clock. J Biol Rhythms 18, 195-205.

Liu, Y., and Bell-Pedersen, D. (2006). Circadian rhythms in Neurospora crassa and other filamentous fungi. Eukaryot Cell 5, 1184-1193.

Liu, Y., Garceau, N.Y., Loros, J.J., and Dunlap, J.C. (1997). Thermally regulated translational control of $\mathrm{FRQ}$ mediates aspects of temperature responses in the neurospora circadian clock. Cell 89, 477-486.

Liu, Y., Loros, J., and Dunlap, J.C. (2000). Phosphorylation of the Neurospora clock protein FREQUENCY determines its degradation rate and strongly influences the period length of the circadian clock. Proc Natl Acad Sci U S A 97, 234-239.

Loros, J.J., and Dunlap, J.C. (2001). Genetic and molecular analysis of circadian rhythms in Neurospora. Annu Rev Physiol 63, 757-794.

Lowrey, P.L., and Takahashi, J.S. (2000). Genetics of the mammalian circadian system: Photic entrainment, circadian pacemaker mechanisms, and posttranslational regulation. Annu Rev Genet 34, 533-562.

Luo, C., Loros, J.J., and Dunlap, J.C. (1998). Nuclear localization is required for function of the essential clock protein $F R Q$. EMBO J 17, 1228-1235.

Mehra, A., Baker, C.L., Loros, J.J., and Dunlap, J.C. (2009a). Posttranslational modifications in circadian rhythms. Trends Biochem Sci 34, 483-490.

Mehra, A., Shi, M., Baker, C.L., Colot, H.V., Loros, J.J., and Dunlap, J. C. (2009b). A role for casein kinase 2 in the mechanism underlying circadian temperature compensation. Cell 137, 749-760.

Neiss, A., Schafmeier, T., and Brunner, M. (2008). Transcriptional regulation and function of the Neurospora clock gene white collar 2 and its isoforms. EMBO Rep 9, 788-794.

Pregueiro, A.M., Liu, Q., Baker, C.L., Dunlap, J.C., and Loros, J.J. (2006). The Neurospora checkpoint kinase 2: a regulatory link between the circadian and cell cycles. Science 313, 644-649.

Price, J.L., Blau, J., Rothenfluh, A., Abodeely, M., Kloss, B., and Young, M.W. (1998). Double-time is a novel Drosophila clock gene that regulates PERIOD protein accumulation. Cell 94, 83-95.
Querfurth, C., Diernfellner, A., Heise, F., Lauinger, L., Neiss, A., Tataroglu, O., Brunner, M., and Schafmeier, T. (2007). Posttranslational regulation of Neurospora circadian clock by CK1a-dependent phosphorylation. Cold Spring Harb Symp Quant Biol 72, 177-183.

Reppert, S.M. (2006). A colorful model of the circadian clock. Cell 124, 233-236.

Sargent, M.L., and Woodward, D.O. (1969). Genetic determinants of circadian rhythmicity in Neurospora. J Bacteriol 97, 861-866.

Sargent, M.L., Briggs, W.R., and Woodward, D.O. (1966). Circadian nature of a rhythm expressed by an invertaseless strain of Neurospora crassa. Plant Physiol 41, 1343-1349.

Sathyanarayanan, S., Zheng, X., Xiao, R., and Sehgal, A. (2004). Posttranslational regulation of Drosophila PERIOD protein by protein phosphatase 2A. Cell 116, 603-615.

Schafmeier, T., Haase, A., Káldi, K., Scholz, J., Fuchs, M., and Brunner, M. (2005). Transcriptional feedback of Neurospora circadian clock gene by phosphorylation-dependent inactivation of its transcription factor. Cell 122, 235-246.

Schafmeier, T., Diernfellner, A., Schäfer, A., Dintsis, O., Neiss, A., and Brunner, M. (2008). Circadian activity and abundance rhythms of the Neurospora clock transcription factor WCC associated with rapid nucleo-cytoplasmic shuttling. Genes Dev 22, 3397-3402.

Shearman, L.P., Sriram, S., Weaver, D.R., Maywood, E.S., Chaves, I., Zheng, B., Kume, K., Lee, C.C., van der Horst, G.T., Hastings, M. $\mathrm{H}$., et al. (2000). Interacting molecular loops in the mammalian circadian clock. Science 288, 1013-1019.

Shi, M., Collett, M., Loros, J.J., and Dunlap, J.C. (2009). FRQinteracting RNA helicase (FRH) mediates negative and positive feedback in the neurospora circadian clock. Genetics 184, 351-361.

Shirogane, T., Jin, J., Ang, X.L., and Harper, J.W. (2005). SCFbetaTRCP controls clock-dependent transcription via casein kinase 1dependent degradation of the mammalian period-1 (Per1) protein. J Biol Chem 280, 26863-26872.

Talora, C., Franchi, L., Linden, H., Ballario, P., and Macino, G. (1999). Role of a white collar-1-white collar-2 complex in blue-light signal transduction. EMBO J 18, 4961-4968.

Tang, C.T., Li, S., Long, C., Cha, J., Huang, G., Li, L., Chen, S., and Liu, Y. (2009). Setting the pace of the Neurospora circadian clock by multiple independent FRQ phosphorylation events. Proc Natl Acad Sci USA 106, 10722-10727.

Taylor, S.S., Kim, C., Vigil, D., Haste, N.M., Yang, J., Wu, J., and Anand, G.S. (2005). Dynamics of signaling by PKA. Biochim Biophys Acta 1754, 25-37.

Tralau, T., Lanthaler, K., Robson, G.D., and Crosthwaite, S.K. (2007). Circadian rhythmicity during prolonged chemostat cultivation of neurospora crassa. Fungal Genet Biol 44, 754-763.

Vanácová, S., Wolf, J., Martin, G., Blank, D., Dettwiler, S., Friedlein, A., Langen, H., Keith, G., and Keller, W. (2005). A new yeast poly (A) polymerase complex involved in RNA quality control. PLoS Biol 3, e189.

Vanselow, K., Vanselow, J.T., Westermark, P.O., Reischl, S., Maier, B., Korte, T., Herrmann, A., Herzel, H., Schlosser, A., and Kramer, A. (2006). Differential effects of PER2 phosphorylation: molecular basis for the human familial advanced sleep phase syndrome (FASPS). Genes Dev 20, 2660-2672.

Vitalini, M.W., Morgan, L.W., March, I.J., and Bell-Pedersen, D. 
(2004). A genetic selection for circadian output pathway mutations in Neurospora crassa. Genetics 167, 119-129.

Williams, S.B. (2007). A circadian timing mechanism in the cyanobacteria. Adv Microb Physiol 52, 229-296.

Wu, G., Xu, G., Schulman, B.A., Jeffrey, P.D., Harper, J.W., and Pavletich, N.P. (2003). Structure of a beta-TrCP1-Skp1-betacatenin complex: destruction motif binding and lysine specificity of the SCF(beta-TrCP1) ubiquitin ligase. Mol Cell 11, 1445-1456.

Xu, Y., Padiath, Q.S., Shapiro, R.E., Jones, C.R., Wu, S.C., Saigoh, N., Saigoh, K., Ptácek, L.J., and Fu, Y.H. (2005). Functional consequences of a CKIdelta mutation causing familial advanced sleep phase syndrome. Nature 434, 640-644.

Xu, Y., Toh, K.L., Jones, C.R., Shin, J.Y., Fu, Y.H., and Ptácek, L.J. (2007). Modeling of a human circadian mutation yields insights into clock regulation by PER2. Cell 128, 59-70.
Yang, Y., Cheng, P., Zhi, G., and Liu, Y. (2001). Identification of a calcium/calmodulin-dependent protein kinase that phosphorylates the Neurospora circadian clock protein FREQUENCY. J Biol Chem 276, 41064-41072.

Yang, Y., Cheng, P., and Liu, Y. (2002). Regulation of the Neurospora circadian clock by casein kinase II. Genes Dev 16, 994-1006.

Yang, Y., Cheng, P., He, Q., Wang, L., and Liu, Y. (2003). Phosphorylation of FREQUENCY protein by casein kinase II is necessary for the function of the Neurospora circadian clock. Mol Cell Biol 23, 6221-6228.

Yang, Y., He, Q., Cheng, P., Wrage, P., Yarden, O., and Liu, Y. (2004). Distinct roles for PP1 and PP2A in the Neurospora circadian clock. Genes Dev 18, 255-260.

Young, M.W., and Kay, S.A. (2001). Time zones: a comparative genetics of circadian clocks. Nat Rev Genet 2, 702-715. 